\title{
CAPITALES EN EL AZÚCAR. LOS HACENDADOS CUBANOS ANTE LA RENTABILIDAD ECONÓMICA Y LA OPORTUNIDAD DE INVERSIÓN (1878-1895)
}

POR

\author{
JOSÉ A. PIQUERAS ARENAS \\ Universidad Jaume I
}

\begin{abstract}
Estudio de los grandes hacendados y en particular de las estrategias de diversificación que utilizaron a la hora de invertir en el azúcar y en otras actividades alternativas en Cuba y en el exterior. Las inversiones en cada uno de estos sectores y actividades guardó más relación con un cálculo de rendimientos que con la falta de recursos financieros.
\end{abstract}

\section{INTRODUCCIÓN}

En las dos últimas décadas del siglo XIX el complejo económico social cubano del azúcar —en afortunada caracterización de Moreno Fraginals- experimentó una amplia y profunda transformación como consecuencia de la Guerra de los Diez Años y de los cambios verificados en el mercado internacional del dulce.

Las explicaciones coinciden al destacar la crisis de la producción tradicional, el cambio en la propiedad de cierto número de ingenios como realización de créditos y embargos, la apertura de un proceso de concentración de ingenios, la separación del cultivo y la fabricación, la descentralización agrícola y la formación de grandes centrales industriales, la absoluta dependencia del mercado norteamericano, todo ello en un contexto de modificación del sistema de trabajo mediante la abolición de la esclavitud y la generalización del trabajo libre. Fue lo que hace años Leland Jenks calificó como "revolución del azúcar", el conjunto de medidas encaminadas a "producir más 
barato y eficazmente" para hacer frente a la superproducción mundial y al descenso de los precios internacionales y de los rendimientos internos ${ }^{1}$.

Las condiciones en que los hacendados azucareros desarrollaron en Cuba sus actividades económicas entre el Pacto del Zanjón y la guerra de 1895 influyeron de forma decisiva en el ritmo e intensidad de los cambios. La imposición de la Metrópoli de elevadas cargas fiscales y del pago de la deuda, la ausencia de un sistema financiero adecuado a las necesidades agrarias e industriales de la Isla, la modificación de la demanda norteamericana y las exigencias del trust refinador dificultaron el proceso de reestructuración al provocar, según se afirma, la ausencia de los capitales necesarios para acometer los cambios. Sólo un corto número de comerciantes-hacendados pudo realizar las inversiones exigidas mientras se sucedían las quiebras de ingenios y no pocos plantadores abandonaban la fabricación para refugiarse en el cultivo.

Observado el fenómeno en perspectiva, la crisis y la desigual repercusión de sus efectos impulsó una transformación inaplazable del sistema azucarero cubano cuya necesidad venía señalándose desde la década de 1860 , pero que se había pospuesto gracias a las ventajas proporcionadas por los bajos costes de producción, la posición dominante en el mercado internacional y los buenos precios alcanzados por el dulce. La crisis obligó a reformar a fondo el complejo azucarero: suprimió las unidades menos eficientes, facilitó la especialización, empujó la adquisición de moderna maquinaria por quienes se mantuvieron o entraron en el negocio, promovió la concentración y la centralización al desplazar a los propietarios de menores recursos y abaratar el precio de las propiedades, creó, en suma, nuevas oportunidades de inversión. La crisis, junto a la abolición de la esclavi-

\footnotetext{
1 Leland JENKs, Nuestra colonia de Cuba, La Habana, Edición Revolucionaria, 1966, pp. 56-60. Ramiro GUERRA, Azúcar y población en las Antillas, La Habana, Ciencias Sociales, 1970, pp. 62-68. H.E. FRIEDLAENDER, Historia económica de Cuba, La Habana, Jesús Montero Editor, 1944, pp. 424-425 y 435-445. Julio Le RiverEnd, Historia económica de Cuba, La Habana, Instituto Cubano del Libro, 1974 (4a. ed.), pp. 457 y ss. Manuel MoRENo Fraginals, "Plantaciones en el Caribe: el caso Cuba-Puerto Rico-Santo Domingo (1860-1940)", en La historia como arma y otros estudios sobre esclavos, ingenios y plantaciones, Barcelona, Crítica, 1983, pp. 56-117. Fe IGLESIAS, "El desarrollo capitalista de Cuba en los albores de la época imperialista", en Instituto de Historia de Cuba, Historia de Cuba, 2. Las luchas por la independencia nacional y las transformaciones estructurales, 1868-1898, La Habana, Editorial Política, 1996, pp. 156-208.
} 
tud, dio lugar a las circunstancias para la expansión del colonato. Los antiguos planes defendidos por Ramón de la Sagra en 1845 y por el conde de Pozos Dulces en los cincuenta, ensayos prematuros de centralización como el de "La Gran Azucarera" en 1858, pudieron llevarse a cabo en condiciones difíciles y con un coste social importante para la antigua clase de hacendados, diezmada por efecto de la guerra, la desaparición del trabajo esclavo, los bajos precios y la ausencia de crédito.

Los cambios finalmente llegaron cuando no pudo seguir produciéndose como antes y después de agotar al máximo las posibilidades del régimen esclavista. Llegaron impuestos por una acusada pérdida de competitividad y debieron acometerse quizá en las peores condiciones.

La valoración del proceso de reestructuración agroindustrial cubano se ha realizado a menudo anteponiendo consideraciones sociopolíticas en lugar de partir de un análisis económico del que extraer después las conclusiones sociales y políticas que pudieran derivarse. Así, se ha afirmado que el sistema esclavista y el régimen colonial imposibilitaron la acumulación de capitales necesarios para acometer la renovación del sector azucarero, como lo probaría el declive de la mayoría de los hacendados, en gran medida criollos, incapaces de seguir el curso de los avances económicos.

Este enfoque parte de una identificación económica y social discutible que consiste en esperar de los hacendados criollos que antepusieran su cubanidad a los lazos con la Metrópoli. El declive de muchos de ellos o su desplazamiento de los núcleos decisivos de la economía insular se ha interpretado, en consecuencia, como una muestra más del dominio colonial, desligándose su suerte de la evolución objetiva de las relaciones económicas, en las que la dependencia colonial juega un papel importante pero no puede hacer olvidar que la mayor contradicción presente en Cuba era de índole social y a ella se debía precisamente la persistencia de las relaciones coloniales. La patria del hacendado en activo comenzaba y concluía en el azúcar; criollo o peninsular, sus actitudes no diferían demasiado y su cohesión social estaba por encima de otras consideraciones. De origen criollo o peninsular, se dejaron llevar por el "frío cálculo del beneficio". Desaparecido este último, el hacendado quebrado podía sentirse más proclive a descubrir sus raíces, como en 1868 lo habían hecho los cafetaleros arruinados y los dueños de pequeños 
trapiches sublevados en Bayamo y Camagüey. El autonomismo se presentaba en los años ochenta como una opción moderada que tal vez pudiera frenar su decadencia, algo que no logró siquiera detener la república.

El análisis social del proceso de transformación económica verificado entre 1878 y 1895 ha centrando demasiado la atención en los hacendados que no lograron modernizar sus unidades productivas, imponiéndose la perspectiva nacional democrática que proyectaba en dicho grupo social la necesidad de una burguesía azucarera cubana, mientras sus dificultades han sido tomadas como exponente de las dificultades generales. Esta visión, con matices, fue compartida a finales del Ochocientos por los autonomistas y nacionalistas, y la volvemos a encontrar en un historiador tan influyente en la posterior historiografía cubana como Ramiro Guerra, descendiente a la postre de una familia agrícola que hacia 1885 convirtió su ingenio en una colonia cañera y que en Azúcar y población en las Antillas, en 1927, reivindicaba frente al latifundio la opción histórica de los pequeños y medianos propietarios como base de existencia de la nación.

La ausencia de capitales fue señalada por numerosos contemporáneos y por autores recientes como la causa de la dispar evolución de los hacendados, a ella se ha atribuido los problemas del sector, su lenta transformación y la ruina de la mayoría ${ }^{2}$. Sin embargo la ausencia de capitales nunca dejó de ser un concepto relativo en Cuba y en ninguna época lo fue tanto como en el período intermedio de las guerras de independencia. Pues las evidencias confirman la existencia de recursos en grandes proporciones e incluso la llegada de capitales nuevos al azúcar procedentes del comercio, de los servicios y del préstamo, en la reanudación de un ciclo similar, aunque con peculiaridades, al que se conoció en décadas anteriores. Esos capitales no estuvieron disponibles para los pequeños y medianos propietarios de ingenios porque éstos carecían de crédito, es decir, de garantía suficiente con la que responder a los préstamos. Endeudados ya, con la abolición de la esclavitud perdieron su principal activo y la refe-

2 Ramiro Guerra [1], p. 64. Raúl CEPERo Bonilla, Azúcar y abolición, Barcelona, Crítica, 1976, p. 209, atribuyó la falta de capital a la imposibilidad de su acumulación en el sistema esclavista. Julio Le RIVEREND [1], pp. 523-524, imputa a la guerra la pérdida de capitales. Para Fé IGLESIAS [1], p. 190, la "baja disponibilidad de capitales para financiar la producción y saldar los créditos, constituía uno de los obstáculos fundamentales para el desarrollo capitalista".

R. I., $1998, \mathrm{n}^{\circ} 212$ 
rencia sobre la que descansaba la refacción, calculada hasta entonces en la capacidad de producir azúcar a partir del factor trabajo empleado en el ingenio. De ahí los elevados intereses, su carácter usurario y la preferencia de las escasas instituciones financieras y de los banqueros particulares por otros destinos para sus préstamos.

Poco se ha reflexionado sobre la decadencia de los hacendados, tomados en conjunto, en relación con su desaparición como clase esclavista y su compleja adaptación a las relaciones capitalistas de producción, a las que accedían previa descapitalización de su principal inmovilizado, la dotación esclava, y ante un mercado de trabajo libre cuyos costes se elevaban en proporción similar al descenso del precio del azúcar.

Nuestra atención se centrará en los grandes hacendados, dueños de capitales acumulados en la esclavitud y de los mayores ingenios, llamados por ello a protagonizar la transformación del complejo económico social del azúcar. Según la hipótesis de la que partimos, como es sabido en parte respondieron al reto, pero cuando no lo hicieron o limitaron su implicación en el proceso fue por motivos distintos de la falta de recursos financieros ${ }^{3}$ y obedeció a un cálculo de rendimientos en el que se tuvo en cuenta la oportunidad de inversión en el azúcar y en otras actividades alternativas en Cuba y en el exterior. En consecuencia, el azúcar atrajo únicamente una parte de sus caudales, lo que retrasó un proceso de concentración y centralización - por debajo de las oportunidades que ofrecía el mercado de la tierra-, y contribuyó a crear la opinión sobre la ausencia de recursos financieros en la Isla.

La verificación de nuestra hipótesis pasa por reconstruir las condiciones de reproducción de capitales en el azúcar, interrogarnos por las causas que desalentaron la reinversión de los beneficios y contrastar la existencia de capitales excedente y la estrategia de diversificación practicada.

3 En 1880 se afirma que los mayores hacendados se hallaban "en condiciones de crédito instantáneo". Eran, entre otros, los herederos de Zulueta y de Baró, Ariosa, Gutiérrez, Pedroso, Aguirre, Soler, Castañer e Ibáñez Palenciano, según Francisco Alejo DE LA TORRE, Ingenios Centrales, La Habana, Imprenta de E. Cosculluela, 1880, p. 24. 


\section{EL MERCADO INTERNACIONAL}

El problema de la reproducción de capitales en el azúcar radicó en la estructura productiva, como más adelante tendremos ocasión de comprobar, pero ya que fue la modificación del mercado internacional lo que desencadenó la crisis y puso en evidencia los desajustes internos, comenzaremos por analizar los aspectos que guardan relación con la comercialización del dulce 4 .

La reducción del peso de la producción cubana en la producción mundial se produjo en coincidencia con el inicio de la guerra, precisamente cuando se lograban las mayores zafras obtenidas hasta entonces e incluso durante varios años se ganó cuota en la producción de azúcar de caña (Cuadro 1). Fue también la época de fuerte crecimiento de las exportaciones hacia los Estados Unidos sin perder por ello volumen de ventas en Europa. En 1876 cayó la producción una

\section{CUADRO 1. PRODUCCION Y EXPORTACION DE AZUCAR CUBANO}

\begin{tabular}{ccccccccc}
\cline { 2 - 8 } & \multicolumn{3}{c}{ Producción azucarera } & \multicolumn{4}{c}{ Exportación de azúcar (Tm.) } \\
\cline { 2 - 8 } Año & Tm. & $\begin{array}{c}\text { \% azucar } \\
\text { munidial }\end{array}$ & $\begin{array}{c}\text { \% caña } \\
\text { mundial }\end{array}$ & EEUU & $\begin{array}{c}\text { Gran } \\
\text { Bretaña }\end{array}$ & Francia & España \\
\hline 1868 & 720.250 & 28,57 & 40,90 & 390.228 & 160.361 & 67.003 & 29.272 \\
1873 & 742.843 & 24,68 & 41,02 & 455.417 & 160.713 & 21.974 & 34.616 \\
1878 & 553.364 & 15,81 & 29,36 & 449.217 & 43.586 & 10.194 & 16.785 \\
1883 & 601.426 & 13,25 & 27,12 & 521.687 & 17.516 & - & 12.999 \\
1888 & 662.758 & 11,20 & 28,09 & 530.492 & 17.010 & - & 35.014 \\
1893 & 945.053 & 12,77 & 26,49 & 866.690 & 4.041 & - & 10.324 \\
\hline
\end{tabular}

Fuente: M. MoREno Fraginals, El Ingenio, La Habana, Ciencias Sociales, 1978, III, pp. 37-38 y 71-72.

sexta parte pero mientras la aportación al azúcar mundial retrocedió medio punto porcentual, el descenso respecto a la producción de azú-

4 Un enfoque del problema desde la perspectiva comercial en Doria GoNZÁLEZ, "El mercado mundial azucarero y su incidencia en la crisis definitiva esclavista", Julio LE RIVEREND et al, Temas acerca de la esclavitud, La Habana, 1988, Ciencias Sociales, pp. 145-166.

R. I., $1998, \mathrm{n}^{\circ} 212$ 
car de caña fue del 6,56\%. Después de esas fechas la presencia cubana se mantuvo en valores estables en el conjunto de la producción de azúcar de caña pero se hundió en poco tiempo a casi la mitad respecto a la producción mundial. En dos fases sucesivas e inmediatas el azúcar cubano retrocedió ante la competencia de la caña de otras regiones y de la remolacha, cuyo crecimiento venía con fuerza desde atrás, con la fuerza que le proporcionaba una política de primas a la fabricación y a la exportación y el desarrollo de una industria muy tecnificada.

La competencia de la remolacha europea fue señalada en Cuba como la principal causa del descenso de los precios y del desalojo de aquellos mercados. Sin embargo los progresos realizados por su competidora no sólo eran conocidos desde los años 1820 sino que en diferentes momentos la Isla se había beneficiado de los adelantos técnicos realizados en el Viejo continente. La producción de remolacha había estado unida inicialmente a la renovación de la agricultura y a la introducción de cultivos escardadores y fertilizantes en sustitución del barbecho. De la planta forrajera y comestible se había pasado a la remolacha industrial por su fácil cultivo y elevado contenido de sacarosa pese al inconveniente de tratarse de una planta bianual.

En los años 1870-1880 se asistió a un gran crecimiento del azúcar de caña en diferentes lugares del mundo que sirvieron para poner de relieve los problemas estructurales de la producción cubana. Java, Hawaii y Filipinas ilustran esa tendencia. En los dos primeros casos la industria azucarera se había constituido en los años 1840 y 1860 con la división del trabajo agrícola e industrial que en 1880 se iniciaba en Cuba. Java conocía el sistema de incentivos implantado por la administración colonial holandesa y Hawaii se benefició desde 1877 de su integración aduanera en los Estados Unidos. El caso de Filipinas es distinto, ya que compartía metrópoli con Cuba y no gozaba de privilegios de ningún tipo como sucedía con las anteriores. Los costes de producción y la superior reducción de fletes desde el sureste asiático con Europa permitían colocar en Londres la libra de azúcar filipina hasta un 30\% más barata que la cubana. Igual sucedía con Java, convertida en el primer proveedor de azúcar de caña del mercado británico. Hasta Perú y Chile, a mayor distancia de Inglaterra, tenían una presencia superior a la cubana en el mercado londinense del azúcar, donde la 
caña iba retrocediendo pero todavía representaba en 1886 el $48 \%$ y en 1889 el $35 \%$ de las importaciones 5 .

Cuba estaba perdiendo terreno frente a la remolacha y ante la caña de otros países. Sus mayores costes de producción le desplazaban de mercados en ascenso en coincidencia con un aumento mundial del consumo de azúcar propiciada por el crecimiento económico, la moderación de los precios y los nuevos hábitos unidos al desarrollo industrial, entre ellos el elevado consumo de bebidas estimulantes (café, té, chocolate) e hidratos energéticos. En los años ochenta el azúcar cubano prácticamente desaparece de los mayores mercados consumidores de azúcar per capita con la excepción de los Estados Unidos. Mientras el consumo per capita en los Estados Unidos fue de 52,31 libras de media en la década de 1880 y se situó en 63,8 libras en 1893, el consumo medio en Gran Bretaña se situó en la década de 1880 en 78,9 libras per capita y año, sin dejar de crecer6. La mayor población del primero (50,2 millones frente a 35,3 en 1880), su fuerte ritmo inmigratorio y su proximidad compensaron a corto plazo las pérdidas al precio de concentrar las exportaciones en un destino y hacerlas más vulnerables. Refugiado en un mercado, Cuba se verá obligada para conservarlo a competir con la productividad remolachera europea y cañera de Asia cuya evolución determinaba también la evolución de los precios. Debió además responder al tipo de demanda requerida.

La caída del precio internacional del azúcar fue la consecuencia del incremento mundial de la producción, de los bajos precios ofrecidos por la remolacha europea gracias a las primas a la exportación, a la elaboración de un azúcar centrífuga uniforme $96^{\circ}$ pol., a los cambios realizados en el proceso de envase y almacenamiento, a la reducción de los fletes y a los nuevos métodos de comercialización con la creación de mercados de futuros que otorgaba a refinadores,

5 The Statesman's Year Book, 1890, cit. por Comisión de Propaganda del Fomento del Trabajo Nacional, La cuestión cubana. Contestación a las exposiciones que han elevado diversas corporaciones de la Isla de Cuba al Excmo. Sr. Ministro de Ultramar, Barcelona, Impr. Hispano-Americana, 1890, p. 32. Para importaciones de Filipinas y otras procedencias, pp. 23-24.

6 Pablo de Alzola, Relaciones comerciales entre la Península y las Antillas, Madrid, Impr. Minuesa de los Ríos, p. 134 y Noel DEERr, The History of Sugar, Londres, Chapman and Hall, 1950, vol. II, p. 532.

R. I., $1998, \mathrm{n}^{\circ} 212$ 
banqueros y especuladores una gran poder decisorio ${ }^{7}$. El promedio de las primas a la producción y a la exportación del azúcar alemán en la segunda mitad del siglo XIX se situó en 0,352 centavos de peso por libra, siendo particularmente importante entre 1882 y $1888^{8}$. El precio de Londres, primer mercado mundial, servía para fijar el precio internacional del azúcar (Cuadro 2).

\section{CUADRO 2. PRECIOS DEL AZÚCAR CRUDO EN EL MERCADO DE LONDRES}

(centavos de peso por libra de azúcar)

\begin{tabular}{cccccc}
\hline Año & Precio & Año & Precio & Año & Precio \\
\hline 1868 & 5,15 & 1878 & 4,68 & 1888 & 3,04 \\
1869 & 5,62 & 1879 & 4,45 & 1889 & 3,75 \\
1870 & 5,38 & 1880 & 4,79 & 1890 & 3,04 \\
1871 & 5,96 & 1881 & 4,96 & 1891 & 3,15 \\
1872 & 5,96 & 1882 & 4,68 & 1892 & 3,15 \\
1873 & 5,26 & 1883 & 4,45 & 1893 & 3,33 \\
1874 & 5,02 & 1884 & 3,10 & 1894 & 2,62 \\
1875 & 4,68 & 1885 & 3,15 & 1895 & 2,34 \\
1876 & 5,02 & 1886 & 2,74 & & \\
1877 & 5,72 & 1887 & 2,74 & & \\
\hline
\end{tabular}

Fuente: Noel Deerr, The History of Sugar, Londres, Chapman and Hall, 1950, II, p. 531. Elaboración a partir de chelines y peniques por hundredweigth (sh. per cwt.). Conversión constante de una libra esterlina por 5,25 pesos. El precio comprende coste, seguros y fletes.

La importancia creciente del azúcar alemán en el mercado londinense influyó en la fijación de los precios en esa plaza. La casa importadora Atkins que operaba en Cuba afirmó que los refinadores norteamericanos pagaban en Nueva York según el precio cotizado en Hamburgo, opinión ampliamente difundida ${ }^{9}$. Sin duda la tendencia del precio en los Estados Unidos siguió la evolución de la coti-

7 M. Moreno Fraginals, El ingenio. Complejo económico social cubano del azúcar, La Habana, Ciencias Sociales, 1978, vol. III, pp. 16-29; con mayor precisión en [1], pp. 57-70.

8 Noel DERr, [6], II, p. 504.

9 Informe reproducido en Porter, Industrial Cuba, cit. por H.E. FRIEDLAENDER [1], p. 435. Manuel MoRENo FraGinALS, [7], II, p. 219, señala también el mayor peso de Hamburgo en la fijación de precios. 
zación inglesa pero la media entre 1883 y 1895 fue superior en un $6,2 \%$ a la británica y en cuatro de esos trece años llegó a pagarse en Estados Unidos por encima del $18 \%$ más que en Londres (Cuadros 2 y 3). Quizá por ello el exportador cubano subestimó su desalojo de las plazas europeas.

\section{CUADRO 3. PRECIO DEL AZÚCAR EXTRANJERO EN EE UU (centavos de dólar por libra)}

\begin{tabular}{cccccc}
\hline Año & $\begin{array}{c}\text { Crudo } \\
\text { (A) }\end{array}$ & $\begin{array}{c}\text { Promedio } \\
\text { (B) }\end{array}$ & Año & $\begin{array}{c}\text { Crudo } \\
(\mathrm{A})\end{array}$ & $\begin{array}{c}\text { Promedio } \\
(\mathrm{B})\end{array}$ \\
\hline 1873 & 5,37 & & 1888 & 2,50 & 3,32 \\
1877 & 4,04 & & 1889 & 2,75 & 3,98 \\
1878 & 4,91 & & 1890 & 3,21 & 3,06 \\
1879 & 5,06 & & 1891 & 3,28 & 3,13 \\
1883 & 4,41 & & 1892 & 3,03 & 3,16 \\
1884 & 4,37 & & 1893 & 3,93 & 3,52 \\
1885 & 3,61 & 3,03 & 1894 & 3,09 & 2,63 \\
1886 & 2,67 & 2,73 & 1895 & 2,92 & 2,02 \\
1887 & 2,84 & 2,72 & & & \\
\hline
\end{tabular}

Fuentes: (A) Statistical Abstract of the United States, 1894, cit. Pablo de AlzolA, Relaciones comerciales entre la Península y las Antillas, Madrid, Impr. Minuesa de los Ríos, 1895, p. 137, y U.S. Bureau of Statistics, Production and commercial movement of sugar, 1906, cit. Manuel MARTIN RodRIGUEZ, Azúcar y descolonización, Granada, Universidad de Granada, 1982, p. 346; (B) Secretaría de Agricultura, Comercio y Trabajo de Cuba, cit. R. GuERRA, Azúcar y abolición, La Habana, Ciencias Sociales, 1970, p. 228.

Las políticas comerciales de los países consumidores se orientaron en direcciones opuestas. Inglaterra suprimió en 1874 el arancel importador, lo que multiplicó el consumo y ofreció una ventaja de la que Cuba no llegaría a sacar provecho. El resto de los países europeos -incluida la Metrópoli- protegieron sus producciones nacionales de remolacha. Estados Unidos elevó los aranceles en los años 1870 y después inició una política de reducción selectiva auspiciada por los refinadores de modo que el diferencial entre azúcar refinado y crudo inclinó la balanza importadora definitivamente hacia el segundo. La modificación de la demanda norteamericana, convertida en monomercado, obligó a producir azúcar crudo para ser refinado en los Estados Unidos. La división del proceso productivo se confi- 
guraba así en tres fases, las dos primeras en suelo insular, cultivo y fabricación semielaborada, y la tercera, el refino, en la industria estadounidense.

Para que ese sistema funcionara y Cuba ocupara el lugar que el trust refinador con la inestimable cooperación del Congreso le habían reservado, debía especializarse en un tipo de dulce y producirlo a bajo coste de modo que compensara los aranceles de importación, los fletes y los seguros. La competencia del área del Pacífico e incluso alemana obligaba a seguir esa orientación. La demanda de centrífugo uniforme homogeneizó la producción y simplificó el mercado pero la especialización en crudo redujo el valor añadido de las exportaciones y limitó su margen comercial.

Desde los años 1870 y con más nitidez en la década siguiente, el azúcar cubano se vio inmerso en un proceso de integración en la estructura económica norteamericana y no sólo en su mercado, aunque este fue el que obligó a ello y guió sus pasos. Del mismo modo que existía un capital hispano-criollo, fue formándose un capital cubano-norteamericano, al que contribuyeron tanto la alianzas empresariales, con el traslado de sedes sociales de empresas azucareras insulares a los Estados Unidos y la participación financiera norteamericana en aquellas, como las inversiones cubanas en los Estados Unidos y el significativo número de hispano-cubanos que a partir de 1868 adoptaron la ciudadanía norteamericana o se vincularon con ese país por medio de matrimonios ${ }^{10}$.

\section{RENDIMIENTOS INDUSTRIALES Y REPRODUCCION DE CAPITALES}

El conflicto bélico ocultó en buena medida los problemas existentes ante la prioridad concedida al esfuerzo militar y la excepcio-

10 Sólo en la provincia de Matanzas, encontramos que adquieren la ciudadanía norteamericana Carlos de la Rosa (1869), Julián Alfonso (1870) y Francisco Reosell (1880). Laird W. Bergad, Cuban Rural Society in the Nineteenth Century. The Social and Economic History of Monoculture in Matanzas, Princeton University Press, Princeton, 1990, pp. 293-295. En los años 1890 se suman, entre otros, Juan Pedro Baró, Perfecto Lacosta, Andrés Terry, Arturo Averhoff, Domingo González y Alfonso, Cristoban N. Madan, Manuel A. Recio y José Antonio Iznaga. Louis A. PÉrez Jr., Cuba between empires, 1878-1902, University of Pittsburgh Press, Pittsburgh, 1983, p. 391. Entre los criollos estaban casados con norteamericanas Julio Azpeteguía, José Antonio Argudín y del Valle, un hijo de Ibáñez Palenciano. También Fé IgLESIAS, [1], pp. 201-204. 
nalidad de la situación que se vivía, en medio de la cual se confundían los indicios de desajustes en la estructura productiva y mercantil con la distorsión natural debida a la contienda. La pérdida galopante e invariable del peso del azúcar cubano en la producción mundial y los efectos que reportarían no encontró respuestas acertadas hasta mediados de la década de 1880.

Algunos propietarios llamaron la atención sobre los nuevos problemas en fecha temprana sin que se adoptaran las medidas que proponían. José Luis Alfonso dirigió en febrero de 1874 un informe al Intendente Mariano Cancio Villamil en el que advertía de la necesidad de adoptar "nuevos medios para sostener con ventaja la competencia que se nos hace y que, de otra manera, nos llevaría a la más completa ruina", teniendo en cuenta que la emancipación de los esclavos era "más o menos completa e inminente (...) por el creciente desarrollo que en todas partes va teniendo la producción del azúcar, base principal de nuestra riqueza" 11 . Alfonso destacaba los altos costes de producción, al bajo nivel técnico empleado, el déficit de brazos conforme a los métodos tradicionales, el elevado precio de la mano de obra en esas circunstancias y la considerable presión tributaria en relación a los rendimientos líquidos como causas de la reducción de las rentas de la Isla. El problema del azúcar cubano era de índole interna pero "la ventajosa competencia que le hacen los europeos con la remolacha" lo había acentuado. Este veterano hacendado proponía soluciones técnicas y organizativas. Consideraba que el empleo del método de difusión, extendido en Europa, lograría incrementar hasta un $50 \%$ la extracción de azúcar para compensar los rendimientos de la remolacha que con un $12 \%$ de azúcar cristalizable permitía obtener el $8 \%$, mientras que de la caña, con un $18 \%$ cristalizable solo se extraía el $6 \%$ cuando con trenes completos podía proporcionar el $12 \%$ o más. Aunque hoy sabemos que la diferencia de sacarosa contenida en una y otra planta no es tan amplia como sostenían los defensores de la caña y el jugo extraible es superior en la remolacha, los rendimientos industriales europeos eran reales e incluso superiores a los señalados por Alfonso y suponían una ventaja comparativa decisiva.

\footnotetext{
11 José Luis Alfonso, "Sobre el mejoramiento de la situación económica de los ingenios de la Isla de Cuba", 3 de febrero de 1874. Biblioteca Nacional de "José Martí", Colección Manuscritos, Alfonso, núm. 8.
}

R. I., $1998, \mathrm{n}^{\circ} 212$ 
La segunda medida defendida consistía en reducir a la mitad el número de ingenios de modo que la mano de obra disponible fuera más abundante (y, en consecuencia, más barata). Las tierras abandonadas por la caña se destinarían a cultivos de subsistencia, lo que redundaría en el abaratamiento de los precios y en la creación de un fuerte incentivo para la inmigración blanca.

Opiniones similares a la anterior se sucedieron en los siguientes años. A raíz de la información del periódico El León Español sobre cambios de propiedad de varios ingenios y el reparto de tierras en régimen de colonía en algunas fincas de la jurisdicción de Remedios, la Revista Económica recomendaba en 1877 separar el cultivo y la industria e incrementar los rendimientos como únicas vías para hacer frente a la competencia de la remolacha ${ }^{12}$. El 4 de septiembre de 1878 el Círculo de Hacendados y otras corporaciones insulares dirigían a la Corona una exposición en la que señalaban sus principales problemas: la reducción de la producción azucarera, el estado de ruina de la Isla y sobre todo, la expansión de la caña en diferentes países con costes de producción un $40 \%$ inferiores a los cubanos ${ }^{13}$.

La conjunción de una serie de factores había contribuido a ofrecer en los años precedentes una imagen contradictoria y errónea de la industria azucarera y del estado de la economía cubana: el crecimiento global de la demanda exterior entre 1868 y 1875 (723.159 toneladas exportadas de media anual en ocho años, en contraste con las 507.151 de los ocho años anteriores y las $611.577 \mathrm{Tm}$. de los ocho posteriores), la rápida concentración de las ventas en los Estados Unidos (54\% en $1868,71,7 \%$ en 1876 y $81 \%$ en 1877 ) una vez concluye en aquel país la reconstrucción del sur sin que se restablezcan los niveles de producción de azúcar en Louisiana mientras no deja de crecer el consumo, el hecho de que en plena contienda el Occidente de Cuba mantuviera intactos los ingenios y consiguiera incrementar la producción, y el alza del precio del azúcar en esos mismos años crearon una sensación de euforia. La guerra, lejos de interrumpir las actividades económicas coincidía con una fase expansiva en producción y beneficios en el sector azucarero $\mathrm{y}$, por

12 Revista Económica, 6 (25 de julio de 1877), p. 45.

13 Exposición del Círculo de Hacendados, la Junta General del Comercio, la Real Sociedad Económica y la Sección de Agricultura de la misma, autorizada por sus respectivos presidentes en 4 de septiembre de 1878, La Habana, La Propaganda Literaria, 1878. 
ende, en la mayoría de las actividades que se alimentaban de sus efectos derivados.

No todos los hacendados se habían beneficiaron de esta situación. Hubo destrucción de ingenios, pérdida de plantaciones y disminución de la dotación de esclavos como consecuencia de la aplicación de las disposiciones sobre emancipados, de la Ley Moret, de las huidas al campo insurrecto o de resultas de la libertad decretada por la autoridad de la República en Armas en el territorio sobre el que ejerció su poder.

La especulación propia de una situación bélica y la orientación de capitales hacia el avituallamiento militar y civil trastocó los mecanismos crediticios y la refacción de cosechas. Los empréstitos de guerra negociados con el Banco Español de La Habana incidieron en la disponibilidad de recursos financieros. Los hacendados esclavistas, respaldados por los beneficios de la coyuntura y enfrentados a las reformas políticas, administrativas y sociales emprendidas en la metrópoli después de la Revolución de 1868, además de mantener en pie la estructura productiva en esas condiciones, suscribieron títulos de la deuda, proporcionaron fondos para someter la rebelión, organizaron, armaron y sostuvieron batallones de Voluntarios, financiaron el enganche en la Península, sufragaron con generosidad periódicos españoles para crear una opinión favorable a sus intereses y contribuyeron a costear las actividades de las fuerzas políticas afines, entre ellas al movimiento alfonsino. En suma, se comprometieron en el aplastamiento de la insurrección a la vez que asumían costes de carácter político. Y a la vez trasvasaron parte de sus patrimonios al extranjero en mayor medida que en cualquier época anterior, diversificaron riesgos y buscaron inversiones seguras y rentables en Estados Unidos y Europa.

Después de la guerra el panorama cambió con enorme rapidez. En los últimos años de contienda los indicadores comenzaron a invertirse pero, como hemos apuntado, los propietarios podían imputar las causas a la duración de la guerra o a un año adverso. En realidad cambiaba la estructura azucarera internacional en medio de un descenso generalizado de los precios de los productos agrarios y de las materias primas.

La necesidad de recuperar capacidad competitiva se hizo perentoria. En la línea de las preocupaciones expuestas por José Luis Alfonso o por el Círculo de Hacendados, otro importante esclavista,

R. I., 1998, n. ${ }^{\circ} 212$ 
Francisco Feliciano Ibáñez proponía recuperar capacidad de competencia desligando el cultivo de la fabricación y facilitando la concentración que permitiera acceder a una economía de gastos ${ }^{14}$. Los nuevos centrales exigían grandes capitales cuando éstos escaseaban en la Isla - decía - y la mayoría de los propietarios estaban arruinados. Si el valor de los ingenios se calculaba a partir de las zafras y éstas, a su vez, dependían del "número de brazos que el ingenio poseía en propiedad", la falta de estos brazos acrecentada por la abolición que entonces acababa de aprobarse reduciría aún más ese valor mientras la retribución de los patrocinados haría subir los gastos de refacción. Ibáñez se inclinaba por la cooperación que diera lugar a sociedades en las que ocho ingenios se fundieran en un Central, al tiempo que se arrendase la tierra a los cultivadores.

La transformación de cierto número de dueños de ingenios en colonos suministradores de los centrales, una opción que racionalizaba el proceso de producción y que acabaría imponiéndose, halló la resistencia mientras fue posible de los antiguos fabricantes de azúcar que rehusaban verse convertidos en meros cultivadores de caña, y su renuencia a truncar una tradición y una posición no hizo sino terminar de descapitalizarles y multiplicar las quiebras. Como escribió algún diario, la propuesta de Ibáñez suponía para ellos "trocar el dictado de propietario de ingenio por el de colono", haciéndoles "abdicar los derechos del señorío para aceptar las obligaciones del vasallaje"15. El colonato dejaba en manos del cultivador la comercialización del azúcar lo que en años de baja de precios reducía su margen de beneficios. Si disponía de financiación propia y su plantación se hallaba con fácil acceso a varios centrales podía mantener su independencia y negociar el valor de la caña, pero si era refaccionado por el central a cambio de entregarle a moler la caña se convertía en un elemento dependiente. La suerte se antojaba mucho más

14 Francisco Feliciano IBÁÑEZ PALENCIANO, Observaciones sobre la utilidad y conveniencia del establecimiento en esta Isla de Grandes Ingenios Centrales para salvar nuestra agricultura e industria azucarera por el aumento de producción y disminución de gastos, La Habana, Imprenta y Litografía Obispo, 1880.

15 El Avisador Comercial, cit. por Francisco Feliciano IBÁÑEZ, Contestación a las objeciones que se han presentado al proyecto para la creación de Grandes Ingenios Centrales, La Habana, El Sol, 1880, p. 27. 
favorable a quienes accedían al colonato desde la esclavitud o la inmigración porque el pasado siempre era peor ${ }^{16}$.

La expansión del colonato halló algunas otras dificultades de índole interna que hicieron más lenta su difusión. La cuantía de la retribución del colono en azúcar dependía menos de las oscilaciones de su precio como de los rendimientos industriales. En tanto esos rendimientos fueran bajos, el arrobaje, la proporción de azúcar con la que el central retribuía cada cien kilos de caña entregadas a moler, sería reducida. Hacia 1890 se pagaba al colono entre 5 y 5,5 arrobas de azúcar por cada cien kilos de caña molida en las grandes zonas azucareras (Matanzas, Colón, Cienfuegos, Cárdenas); en Manzanillo o Sagua no alcanzaba el 4\%. Tanto se dependía de la evolución de los rendimientos industriales que las primeras asociaciones de colonos reclamaron mantenerse informados por ellos mismos de los progresos que se realizaran en este terreno de modo que los adelantos pudieran traducirse en un incremento del arrobaje ${ }^{17}$. El descenso del precio en el mercado repercutía en la necesidad inmediata del colono de proporcionar más caña para mantener su nivel de ingresos.

La demanda de caña en grandes cantidades para los centrales y la expansión del azúcar por la región centro-oriental no estuvo acompañada de mayores zafras sino cuando la demanda norteamericana se disparó. Pese a coincidir con unos años de bajos precios, sólo a partir de 1891 creció la producción después de tres lustros de declive y estancamiento. Quiere esto decir que el incremento de superficie cultivada se realizó sobre tierras marginales, de menores rendimientos, y sobre suelo virgen que implicaba mayores costes iniciales de explotación.

En Occidente los rendimientos decrecientes, las quiebras y las dificultades de la posguerra supusieron el abandono de zonas de

16 El Ingenio "Congreso", en Puerto Príncipe, pagaba en 1880 a sus arrendatarios las 100 arrobas de caña a $2 / 2,5$ pesos una vez deducidos los adelantos, que venían a representar el 50 por 100 del precio que se pagaba en la provincia cuando la venta estaba límpia de cargas. Cfr. Gastón DESCAMPS, La crisis azucarera y la Isla de Cuba, La Habana, La Propaganda Literaria, 1885, pp. 108 y 124. Sin embargo antes de la implantación de los centrales la remuneración fue inferior. Según Francisco F. IBÁÑEZ PALENCIANo [14], p. 15, las 100 arrobas de caña se pagaban en 1880 en los ingenios a 2 pesos y hasta a 18 rs., cuando él creía que los centrales que propugnaba podían pagarla a 4 y 5 pesos, como así vino a suceder.

17 Julio Le RIVEREND [1], pp. 471-472.

R. I., $1998, \mathrm{n}^{\circ} 212$ 
cultivo y la disminución de la producción de caña ${ }^{18}$. El descenso de los precios puso de relieve la ineficiencia de las explotaciones, los errores en el cultivo y el desajuste de los costes. Cualquier innovación agrícola que se intentara llegaba en el momento en que menor era la remuneración del azúcar, por lo que el incremento de producción debió alcanzarse mediante la extensión de la superficie cosechada en lugar de intensificar la productividad. Conscientes de estos problemas, la burguesía azucarera se interesó por una agricultura más científica, pero ese mayor conocimiento no llegó a trasladarse al cultivo sino en una mínima proporción. La ausencia de una política agraria, el trasvase del cultivo a los sectores económicamente menos potentes y la crisis económica de los ochenta actuaron en contra. El uso de fertilizantes que pudiera regenerar los castigados suelos occidentales apenas fue practicado. De nuevo la lucha por reducir costes ante la caída del precio del azúcar y el aumento del precio de la mano de obra, los elevados impuestos y altos intereses financieros, se conjuró contra las innovaciones y el resultado fue un lento crecimiento de los rendimientos agrícolas por caballería en el conjunto de la Isla.

El panorama en la industria fue diferente aunque enormemente dispar. Avanzaba el proceso de mecanización y de adquisición de trenes completos, y si bien la media indica que entre 1870 y 1890 los ingenios incrementan cuatro veces su capacidad de molienda, sólo un reducido número de centrales eran modernas y disponían de una gran capacidad productiva. La brecha que separaba el núcleo más desarrollado del resto no dejó de ensancharse.

En esa coyuntura de readaptación y competencia con el exterior, la cuestión decisiva de la economía azucarera radica en los rendimientos industriales. El rendimiento industrial establece los rendimientos generales del sector, proporciona los índices de evolución de la productividad, sirve para fijar la retribución del colono y su incremento lo es también de los beneficios empresariales.

Los rendimientos industriales dependían, además de la clase de caña plantada, de dos factores, uno técnico y otro organizativo. El primero exigía la adquisición de moderna maquinaria que completase el proceso de fabricación y lograra extraer el máximo azúcar cristalizable. La mayor tecnificación requería asimismo emplear

18 Laird W. BERGAD, [10], p. 270. 
trabajadores con alguna cualificación a los que entregar el manejo y mantenimiento de las instalaciones.

$\mathrm{El}$ aspecto organizativo no era menos complejo, pues implicaba disponer del máximo de caña que optimizara la inversión realizada y atendiera la superior capacidad de molienda, pero sobre todo, disponer de caña en el momento más adecuado, cuando mayor era su concentración de sacarosa, cosecharla madura, reducir el tiempo de zafra y ejecutarla de manera rápida, lo que a su vez exigía un empleo masivo de brazos y un coste salarial dependiente del volumen de asalariados disponibles. La inmigración temporal peninsular no terminaba de resolver el problema porque hacía depender los jornales de una concurrencia incierta de brazos dispuesta a obtener los mayores ingresos que compensaran la travesía; la procedente de otros lugares se había cerrado después de la experiencia yucatera o se antojaba indeseable, caso de la población antillana. De ahí que se promoviera la colonización interior, capaz de asentar campesinos cuya dedicación preferible fuera la agricultura de subsistencia y estuvieran disponibles para trabajar como asalariados en la zafra, proyecto que nunca llegó a consumarse ante las ventajas que pese a todo ofrecía el cultivo de la caña.

En los años 1878-1895 se asiste en Cuba a un lento crecimiento de los rendimientos industriales medios, a un ritmo inferior a la baja de los precios internacionales del azúcar. Globalmente considerado, suponía el estrangulamiento del proceso económico. Pese a mejorar con el curso del tiempo, se mantuvo el diferencial que le separaba de los rendimientos remolacheros, con consecuencias negativas tanto para la generación de beneficios como para el conjunto de la actividad productiva. Si los rendimientos industriales eran menores y el precio del azúcar tendió a equipararse al de la remolacha, la diferencia de costes hubo de compensarse con una baja retribución del trabajo y la búsqueda de otras ventajas en el mercado. Esas ventajas pasaron por integrarse en la economía azucarera norteamericana aceptando una función subsidiaria de la industria refinadora a la que proporcionaría materia prima, el azúcar crudo. Cuanto mayor fuera la integración más estaría asegurada la demanda, siempre y cuando lograra producirse a costes competitivos y no se interfirieran los intereses metropolitanos con un proteccionismo que dificultaba la relación preferente con el vecino del Norte. El mejor marco de esa integración pasaba por un tratado comercial que facilitase la exportación y,

R. I., $1998, \mathrm{n}^{\circ} 212$ 
más adelante, por un sistema de cuotas que le diera estabilidad. El anexionismo volvió a cobrar carta de naturaleza en los círculos azucareros en vísperas de la guerra de 1895.

La evolución de los rendimientos fue, como se ha indicado, extremadamente lenta. Conviene precisar, no obstante, la dificultad de ofrecer cifras fiables y homologables entre sí dada la diversidad de fuentes, medios de medición y diferente estado de desarrollo tecnológico de los ingenios y centrales. Descamps cifraba en el $6 \%$ el rendimiento medio en Puerto Príncipe en 1880. Es la misma cifra que ofrecen Ibáñez Palenciano para esa fecha y Juan B. Jiménez en Aventuras de un Mayoral en 1883. Le Riverend, además de insistir en el carácter aproximativo de estos datos, añade que hacia 18841886 los trenes jamaiquinos daban una cantidad inferior. Cornelio Coppinger situó en 7,5\% los rendimientos para comienzos de la década y Descamps eleva la cantidad a 9,83\% de promedio entre 1885 y 1889 e incluso el central Constancia afirmó haber llegado al $12,5 \%$. Son estos últimos, a todas luces, rendimientos excepcionales y de inverosímil extensión al conjunto de la producción cubana. Piénsese que el promedio en 1942 era precisamente ese 12,5\% atribuido medio siglo antes y que para 1913 se considera que estaba en el $10,8 \%{ }^{19}$. Y aunque los métodos de medición se habían perfeccionado, la diferencia no se justifica. Las conclusiones de Moreno Fraginals para unos años anteriores vendrían a corroborar la información de Descamps, Ibáñez y Jiménez, y coinciden con las valoraciones de Le Riverend. Para Moreno, los ingenios mecanizados de la década de 1860 podían ofrecer entre un $5 \%$ y un $6 \%$ de rendimiento, que con índices modernos quedaría entre el 4,5\% y el $5,7 \%$ pol 96. En 1873 Juan Poey evaluó en 6,10\% los rendimientos medios de su ingenio "Las Cañas" y afirmó haber llegado al 8\%, cifra que Moreno cree imposible e incluso duda del rendimiento declarado en 1881 por

19 Gastón DesCamps, [16], p. 127. Francisco IBÁÑEz PalEnCiano [14], p. 7. Julio Le RIVEREND

[1], pp. 472 y 500. Los rendimientos de 1942 en José Antonio GuERRA, "La evolución económico-social de la industria azucarera en los últimos años" (1942), apéndice a Ramiro GuerRa [1], p. 261. Para 1913, Antonio SANTAMARía García, "Caña de azúcar y producción de azúcar en Cuba. Crecimiento y organización de la industria azucarera cubana desde mediados del siglo XIX hasta la finalización de la Primera Guerra Mundial", en C. Naranjo, M.A. Puig-Samper y L.M. García Mora, La Nación Soñada: Cuba, Puerto Rico y Filipinas ante el 98, Madrid, Doce Calles, 1996, p. 237. 
el maestro de azúcar de aquel, un $7 \%$ incluyendo el azúcar de miel. En sus viajes por ingenios en 1885 Alvaro Reynoso llegó a saber que el célebre maestro de Poey "daba un rendimiento que no obtenía. Todo era mentira" 20 .

La comparación con los rendimientos de la remolacha se tornaban siempre negativos y se acrecentaban con el transcurso del tiempo. La media en Alemania en la década de 1880 estaba en el 10,95\%, en Francia entre 1886 y 1889 llegaba al 9,64\%, en Rusia al 8,75\%. En la década de 1890 las cifras se situaban en el 12,64\% en Alemania, el $10,50 \%$ en Francia, el $12,06 \%$ en Rusia y el $12,25 \%$ en Austria-Hungría. Ninguno de los países productores de remolacha bajaba del $10 \%$ de extracción de azúcar ${ }^{21}$. Pero según la Revista de Agricultura en 1890 Brasil y Java, sirviéndose del método de difusión, también obtenían de la caña un rendimiento del $12 \%^{22}$. Esta publicación sostenía que "la solución del problema de nuestra industria azucarera, en lo que se relaciona con la baratez del costo de la fabricación, está hoy por hoy, vinculada en el procedimiento de la fabricación". Los análisis sobre los resultados del sistema de difusión en 1890 ofrecían un rendimiento superior en un $2,70 \%$ al habitual del $8,4 \%$, lo que se traducía, deducidos los costes de carbón, en una utilidad añadida del $2,45 \%$. Los ensayos con otros tipos de caña, como la de Luisiana, mejoraban también los resultados ${ }^{23}$.

La información disponible en el ministerio de Ultramar a finales de 1891 indicaba que aunque se habían perfeccionado los procesos de fabricación, pasándose de extraer desde el 5\% de azúcar al 6,5/7\% y hasta un $8 \%$ que se obtenía de media, se estaba lejos de alcanzar una media competitiva. Así, en informe al ministro se decía que "todavía se necesitaba adelantar pues mientras no se llegue al 11 no será todo lo productivo que debe ser pues la remolacha produce el 12 y el $14 " 24$. La diferencia apuntada en 1874 entre el $6 \%$ cubano y el $8 \%$

\footnotetext{
20 Manuel Moreno Fraginals, [7 ], I, p. 254. Alvaro ReYnoso, "Viajes por diversos ingenios, cafetales y otras fincas de la Isla de Cuba (1863-1864)". "Segunda parte del cuaderno (1883-1886)", en Francisco DíAz BARREIRo, "El cuaderno de viajes de Reynoso", Revista de la Biblioteca Nacional José Martí, vol. XXII-1 (1980), p. 87.

${ }^{21}$ Noel DEER, [6], pp. 493-503. Véase también Fé IGLESIAS [1], p. 175 sobre fuentes alemanas.

22 Revista de Agricultura, 2 (12 de enero de 1890) y 34 (31 de agosto de 1890).

23 Revista de Agricultura, 1 (5 de enero de 1890).

24 Archivo Maura (Madrid), Leg. 324, 27, "Precio del azúcar y de la caña".
} 
de la remolacha se había acrecentado a la distancia que mediaba entre el $8 \%$ máximo obtenido en Cuba y el $12 \%$ de media de los rendimientos industriales europeos. Era, sin duda, el principal problema a resolver.

\section{DISPONIBILIDAD DE CAPITALES Y RENTABILIDAD}

El modo de organizar las explotaciones y los bajos rendimientos industriales repercutían de manera directa en la rentabilidad del negocio azucarero: "las empresas más importantes [...], con muy pocas excepciones, no producen una utilidad líquida - cuando dejan utilidad- relacionada con el capital invertido en ellas, como sucede en otras que pueden llamarse medianas, y que por las demás condiciones se hallan en idénticas circunstancias", afirmaba la prensa económica. La recurrente demanda de brazos como causa de los problemas fue contestada en reunión de hacendados por Francisco Zayas: "Señores, - dijo- brazos nos sobran, lo que nos falta son cabezas". Refiriéndose a las ventajas perdidas, el colaborador de $D e$ Indische Mercuur, Luis Engel, concluía que "la edad de oro ha cedido a la lucha de la inteligencia, que es la única que puede establecer competencia y decidir el porvenir de la Isla"25.

Juan Poey redactó en 1880 un informe sobre la rebaja de derechos arancelarios reclamada por los hacendados en la que además de dar su respaldo a la petición indicaba los auténticos problemas del azúcar cubano: "Las verdaderas reformas económicas de Cuba están en los cañaverales", afirmaba ${ }^{26}$. Era preciso mejorar los cultivos y triplicar la producción de cada ingenio a fin de que alcanzaran una rentabilidad remuneradora. Este hacendado, por muchos motivos a la cabeza de la industria azucarera cubana ${ }^{27}$, juzgaba con severidad

\footnotetext{
25 "Industria sacarina", Revista Económica, 66, 14 de enero de 1879, pp. 240-241.

26 "División del trabajo en los ingenios", Revista Económica, 151, 12 de septiembre de 1880 .

27 Poey había sido el único hacendado cubano premiado en la Exposición Universal de Viena en 1873 con la medalla al progreso que reconocía los adelantos en la producción del ingenio "Las Cañas". Julián Zulueta debió conformarse con la medalla de mérito mientras las muestras de Iznaga no merecieron reconocimiento alguno. Juan NAVARRo REVERTER, Del Túria al Danubio. Memorias de la Exposición Universal de Viena, Valencia, Impr. J. Doménech, 1875, pp. 722-724.
} 
la actitud confiada imperante entre los dueños de ingenios, quienes "creyendo que sus azúcares iban a gozar siempre de la preferencia que los mercados extranjeros daban a su industria apenas si se cuidaban de otra cosa que de hacer una zafra más". Según Poey, la ganancia del capital en los ingenios era del $4,13 \%$ antes de deducir intereses, seguros de incendios y huracanes y otros riesgos "a que están expuestos nuestros esclavos y animales", decía quien en 1873 en Viena había declarado emplear 707 operarios y disponer de más de 500 bueyes. Es muy posible que Poey exagerara a la baja la rentabilidad del azúcar pero dado que su planteamiento no consistía en trasladar las deficiencias al sistema fiscal y arancelario, sino llamar la atención sobre reformas en el mismo sistema agroindustrial, la cifra definitiva no debería alejarse demasiado de la indicada. De hecho en 1873 había declarado al periodista Antonio Gallenga que los ingenios más adelantados proporcionaban una rentabilidad de entre el 6 y el 8,5\% antes de descontar los gastos de refacción ${ }^{28}$.

Mientras la reestructuración del azúcar reclamaba capitales, esos recursos se orientaban a financiar la deuda o a otras formas especulativas, incluidas las contratas oficiales y las obras urbanas. Negocios que se antojan más rentables que refaccionar cosechas de dudosa comercialización. En suma, los dueños de capitales que a la vez son propietarios de ingenios invierten en nueva maquinaria y nuevos procesos, pero optan por diversificar sus inversiones y limitan el riesgo.

A través de un caso podemos conocer algo más de las actitudes imperantes en ese final de etapa colonial. Dueño de uno de los mayores capitales de la Isla y en condiciones de crédito, según testimonios antes citados, en agosto de 1883 Ibáñez Palenciano reclamaba por el embargo del ingenio de su propiedad "San Joaquín" a causa de las deudas contraidas con Demetrio Pérez de la Riva ${ }^{29}$. Ibáñez amenazaba con acudir a la vía judicial a la vez que solicitaba medidas administrativas contra el Director general de Hacienda de Matanzas por haber ordenado el embargo, en su opinión improcedente. Pérez de la Riva aparece como dueño del ingenio "Cantabria" y, muy posible, era uno de los proveedores de caña a los centrales de Ibáñez que no había percibido el precio cuando la campaña había concluido. El "San Joaquín" y el "Cantabria" se hallaban en Colón,

28 A. Gallenga, The Pearl of the Antilles, Londres, Chapman and Hall, 1873, p. 125.

29 Archivo Nacional de Cuba, Miscelánea Expedientes, Leg. 46, N. 
ambos en el partido de Macurijes ${ }^{30}$. De Pérez de la Riva sabemos que era un abogado andaluz instalado en Marianao y que poco después, en 1885 , se haría con la propiedad de dos ingenios más para dedicarlos al cultivo de caña, el "Isabel" y el "Elena", adquiridos en Matanzas a los quebrados herederos de Cosme de la Torriente ${ }^{31}$. Así que la posibilidad del impago de un suministro de caña adquiere visos de realidad.

¿Estamos ante los síntomas del declive del potencial económico de Ibáñez, preclaro introductor del nuevo sistema de producción, como se ha apuntado? Nos inclinamos a pensar que la falta de liquidez puede atribuirse a los problemas coyunturales de la comercialización del dulce. Las dificultades nacidas en el intercambio con los Estados Unidos había provocado el pánico en los medios financieros y ocasionaría entre finales de 1883 y enero de 1884 la suspensión de pagos de siete casas de comercio y el cierre del Banco de Ahorro de La Habana. El precio del bocoy de azúcar descendió de 65/70 pesos a $30^{32}$. En esas condiciones se negoció el Modus Vivendi con los Estados Unidos en diciembre de 1883, finalmente aprobado en febrero de 1884.

Ibáñez no solo conservó el "San Joaquín", sino que en él experimentó en 1891 el sistema de difusión que permitía obtener mejores rendimientos de la caña. Cuando en 1892 fallece Ibáñez Palenciano dos de sus ingenios pasaron a sus acreedores, uno de ellos fabricante de equipos de difusión Fives Lille y Cía., lo que se ha tomado como signo de ruina de unos de los hombres más innovadores de la década de $1880^{33}$.

La información disponible nos lleva a deducir que los sucesores de Ibáñez dejaron embargar esos ingenios cuando disponían de recursos más que suficientes para hacer frente a las deudas. El problema de la ausencia de capitales debe situarse en su justo término: se trata de capitales disponibles para el azúcar. En realidad desde mediados de siglo se estaba produciendo en Cuba una permanente

\footnotetext{
30 "Noticia de las fincas azucareras en producción que existían en toda la Isla de Cuba al comenzar el presupuesto actual de 1877-78", Revista Económica, 37 (7 de junio de 1878), p. 11.

31 Laird W. BERGAD, [10], pp. 296-297 y 400.

32 Herminio PORTELl VILÁ, Historia de Cuba en sus relaciones con los Estados Unidos y España. 1878-1899, 4 Vols., La Habana, Jesús Montero Editor, 1939-1941, p. 37.

33 Julio Le Riverend, [1], p. 499.
} 
transferencia de beneficios y capitales para ser colocados en Europa y Estados Unidos, tendencia que se intensificó a partir de la guerra de 1868.

Asistimos a una cuidada estrategia de diversificación de activos que conduce a situar parte del patrimonio acumulado en la trata, el azúcar y el comercio en el exterior debido a la atracción que ejercen los negocios en Inglaterra, Francia, Estados Unidos y España, casi siempre por ese orden. Así, Ibáñez Palenciano en 1868 tenía colocados en la Península más de 3,3 millones de pesos, por encima del $52 \%$ de su patrimonio total, repartidos en buques y navieras, deuda pública, casas de comercio, participación en empresas y créditos y cuentas corrientes. Otra parte de su fortuna estaba colocada en Inglaterra, donde a finales de siglo sus herederos tenían depósitos e inversiones superiores a las conservadas en $\mathrm{Cuba}^{34}$.

La diversificación no excluía continuar la actividad azucarera en Cuba y hacer lo posible por mejorar las instalaciones y el nivel de beneficios. No existe un desentendimiento del negocio, al menos en los nombres más relevantes, como lo prueba que conservaran sus propiedades y un fondo operativo en la Isla que invirtieron en la industria. Pero una parte sustantiva del patrimonio, si no la mayor parte, era colocada en el exterior en busca de mayores ganancias y de seguridad. A partir de esa situación, demandaron también financiación dentro de la Isla a precio asequible y competitivo, y pudieron verse en aprietos por falta de liquidez en algún momento, como presumiblemente le sucede a Ibáñez en 1883.

Un caso distinto fue el de los hacendados no incluidos en el círculo de mayores propietarios-exportadores, que perdieron posición frente a los comerciantes-prestamistas ante quienes cedieron ingenios y tierras. Porque el acceso a la propiedad siguió, ofreció oportunidades en los años $1880^{35}$, hasta convertirse en una opción incierta en los 1890 pese a la fuerte expansión de las exportaciones hacia los Estados Unidos después de la firma del Tratado de 1891.

Un ejemplo de la desconfianza que merece la adquisición de las explotaciones azucareras lo encontramos en la actitud del capital británico. Dedicado al crédito, a las inversiones en ferrocarriles y

\footnotetext{
34 Angel BAHAmonde y José CAyUELA, Hacer las Américas. Las elites coloniales españolas en el siglo XIX, Madrid, Alianza Editorial, 1992, pp. 368-369.

35 Laird W. BERGAD, [10], pp. 293-296.
} 
minería, proporcionó fuertes sumas a los hacendados azucareros pero se abstuvo de ejecutar las deudas hasta décadas después, renunciando a intervenir en la producción cuando podía hacerlo. La incertidumbre en el sector quizá explique esa cautela. Las causas de esa incertidumbre provenían menos de la situación colonial de la Isla, que incidía en la misma medida en los demás sectores hacia los que se orientó el capital inglés, que de las condiciones del mercado internacional, donde la concentración de las ventas en los Estados Unidos dejaba la colocación de la producción en manos de la política arancelaria que adoptara este país. La excesiva dependencia de la Isla respecto al vecino del norte preocupaba a los inversionistas británicos y retrasaba su entrada en la producción azucarera cuando disponían de hipotecas, préstamos impagados y una amplia experiencia comercializadora. Los inversores británicos, cuyos intereses eran crecientes en la Isla, se mostraron contrarios al tratado de 1891 entre España y los Estados Unidos ya que pensaban que facilitaba la influencia de los norteamericanos en $\mathrm{Cuba}^{36}$.

\section{EL CAPITAL EMIGRADO}

Las grandes fortunas de Cuba hacía tiempo que habían iniciado un proceso de diversificación. De entre los 50 mayores productores de azúcar en los años 1860 podemos destacar la evolución seguida por algunos de los más connotados siguiendo el orden de su relevancia productora dos décadas antes. Se trata sólo de una muestra que no pretende ser exhaustiva pero sí nos indica una tendencia dominante. Algunos han liquidado por completo sus bienes y otros han quebrado, pero de los 20 mayores productores, dos tercios de los ingenios seguían en 1877 en manos de las mismas familias y sólo cinco

\footnotetext{
36 Informe del vicecónsul Ramón O. Williams, 7 diciembre de 1892, en SDA: Consular Despatches-Havana, vol. 113, Williams-Subsecret. Wharton, cit. por Herminio PORTELL VILÁ, [32], pp. 85-86. A cambio de desvincularse del tratado, un sindicato de banqueros anglo-francés se mostró dispuesto a conceder un empréstito a España que permitiera reordenar su deuda interna y cubana si ésta otorgaba la autonomía a la Isla. Funcionarios coloniales ingleses expertos en la organización del Home rule habrían llegado a colaborar en un proyecto. Los autonomistas cubanos estuvieron poco interesados en la operación, ya que su objetivo era precisamente estrechar relaciones con el mercado natural de la Isla y mantenían cordiales vínculos con el consulado norteamericano en La Habana.
} 
habían cambiado de propietario ${ }^{37}$. La relación de hacendados y la evolución de sus patrimonios no puede ser más significativa ${ }^{38}$ :

1) Julián Zulueta tenía en 1864 el $79 \%$ de su patrimonio en Cuba; en 1885 su hijo, Julián Zulueta y Samá, con una fortuna próxima a los nueve millones de pesos, tenía el $48,71 \%$ de sus activos en España, el $30,54 \%$ en Cuba, el $8,93 \%$ en Francia y el $4,14 \%$ en Inglaterra.

2) La condesa de Santovenia, algo más de un millón de pesos de patrimonio, había situado ya en 1876 más de la mitad de su patrimonio entre Inglaterra y España y después de esa fecha fue liquidando sus bienes en Cuba.

3) El marqués de Casa Torres (Anastasio Carrillo Albornoz) había trasvasado en 1871 el $90 \%$ de su millón de pesos a España.

4) El conde de Peñalver (Narciso de Peñalver) tenía en 1888 más del $90 \%$ de sus recursos, millón y medio de pesos, en la Península.

5) El marqués de Casa Brunet (Nicolás Brunet) tenía en 1887 el $53 \%$ de sus bienes en Inglaterra. Su fortuna superaba los tres millones de pesos.

6) El marqués de Casa Montalvo (Ignacio Montalvo), contaba en 1883 con el 52\% de su patrimonio en Inglaterra, el 33\% en España y apenas el $14 \%$ en Cuba. En total disponía de cerca de millón y medio de pesos.

7) Calvo de la Puerta había depositado en 1887 el $35 \%$ de sus bienes en Inglaterra.

8) Du'Quesne contaba en 1888 con más del $30 \%$ de su fortuna en España. Su patrimonio era algo superior al millón de pesos.

9) El conde de Bagaes (Losada Pastor) disponía en 1887 del 62\% de su patrimonio en Inglaterra.

10) El conde de Casa Moré (José Eugenio Moré), un hombre de los años setenta y ochenta, tenía en 1885 en España más del 50\% de

37 La continuidad puede establecerse comparando Carlos REBELLO, Estados relativos a la producción azucarera de la Isla de Cuba, formados competentemente y con autorización de la Intendencia de Ejército y Hacienda, La Habana, s.i., 1860, y "Noticia de las fincas azucareras en producción... de 1877-78", Revista Económica, 37 (7 de junio de 1878), pp. 7-24. Algunas conclusiones, en María del Carmen BARCIA, Burguesía esclavista y abolición, La Habana, Ciencias Sociales, 1987, pp. 81-82.

38 A. BAHAMONDE y J. CAYUELA, [34], passim, y en especial pp. 56-58 y 366-369. 
su fortuna, valorada por encima de nueve millones y medio de pesos.

11) José Antonio Suárez Argudín y del Valle contaba en 1884 con tres millones y medio de pesos, un $75 \%$ de sus activos en Inglaterra, el 11,74\% en España, un 1,26\% en Francia y sólo el $11,19 \%$ en Cuba.

12) Carlos Drake, conde de Vegamar, había trasvasado a España en 1872 el $76 \%$ de su patrimonio, cifrado en millón y medio de pesos, y mantenía en Cuba el 24\%, con tendencia a abandonar la Isla pero conservando todavía ingenios una década después.

13) El conde de Casa Lombillo tenía en 1876 el 53\% de sus bienes en Inglaterra, el $21,5 \%$ en Estados Unidos, el 12,9\% en España y el $12,4 \%$ en Cuba. Su patrimonio ascendía a 4,3 millones.

14) Francisco Feliciano Ibáñez Palenciano, uno de los mayores hacendados cuya familia a diferencia de muchos de los anteriores no abandona la Isla siquiera después de 1898, tenía ya en 1868 en España el 52\% de su formidable fortuna, valorada en 6,1 millones de pesos, y una cifra indeterminada en Gran Bretaña.

Además de los citados, todos insignes patricios desde mediados de siglo, entre las "nuevas" fortunas crecidas con la guerra que alcanzan su máxima influencia en los años 1880 y 1890 tenemos los siguientes:

1) Vicente Galarza, conde de Galarza, contaba en 1886 con más del $40 \%$ de sus activos en España. Su patrimonio superaba los cuatro millones de pesos.

2) Francisco Retortillo Imbrechts, conde de Almaraz, al fallecer en 1887 tenía más del $80 \%$ de sus bienes en España. Su fortuna superaba el millón de pesos.

3) Rafael de Toca y Aguilar, conde de San Ignacio, dueño en 1893 de más de nueve millones de pesos, vinculado al Banco Español de la Isla de Cuba y al Diario de la Marina, además de conservar sus diversos ingenios, tenía en España el 29\% de sus bienes.

4) También la familia Herrera - tan implicada en la vida económica cubana de los ochenta- emprendía su diversificación. A nombre de Julia Herrera consta en España en 1886 más del 50\% de su patrimonio, cifrado en casi un millón de pesos. 
5) Ramón Argüelles, protagonista de grandes inversiones en los años ochenta en ferrocarriles, disponía en 1888 de una fortuna superior a los nueve millones y medio de pesos, el $38 \%$ de la cual estaba situada en España.

6) Rafael Torices, introducido en la producción de azúcar desde el comercio en la década de 1870, tenía en España en 1883 el 45,5\% de su fortuna, que ascendía a cuatro millones y medio de pesos

De los mencionados, prácticamente todos los que habían poseído ingenios azucareros los conservaban y alguno incluso había acrecentado su número, de modo que no puede hablarse de una salida organizada de la producción azucarera.

Entre 1868 y 1890 había depositados en Gran Bretaña 72.679 .804 pesos de matriz cubana. La inversión en España registrada en el mismo periodo indica un monto de $95.556 .844,5$ pesos. En ambos casos aunque en diferente medida, los fondos se emplean en participaciones industriales, casas de comercio, navieras y consignatarias, créditos, valores bursátiles, deuda pública, fincas urbanas, etc ${ }^{39}$. No deja de llamar la atención la inversión en valores exteriores cuando más precisos son los capitales en la Isla. E incluso que se dirijan a la adquisición de deuda española, en donde se colocan 8,3 millones de pesos únicamente de los patrimonios registrados.

Mantener activos en Cuba ofrecía inconvenientes. Mercados inciertos, precios bajos, rentabilidad económica decreciente en el azúcar, dudas sobre el futuro político de la Isla, etc. llevó a que los dueños de capitales diversificaran sus activos: los llevaron consigo al dejar la Isla, los invirtieron en el extranjero o los destinaron a otras actividades. Por lo común no abandonaron la producción de azúcar pero limitaron el inmovilizado. Esa actitud la encontramos tanto en aquellos cuyas propiedades dan muestras de estancamiento como en los que se presentan como más innovadores.

Buena parte de los beneficios generados por la exportación quedaron en el extranjero. De este modo se evitaban las elevadas cargas impositivas sobre bienes, rentas y capitales para hacer frente a un presupuesto hipotecado por los gastos coloniales y la deuda, y se liberaba a las ganancias de la depreciación ocasionada por la inflación que domina la economía de la Isla o la arbitrariedad de un cam-

39 Ibidem, pp. 76 y 148. 
bio ficticio ordenado por la autoridad colonial, que en 1874 había establecido la admisión de la libra esterlina de oro por un valor de 4,44 pesos cuando el par monetario era de 5,25 pesos, y el dólar de plata a la par del peso cuando su cambio metálico estaba en 1,069 pesos $^{40}$.

Los testimonios de la época se hacen eco de la preferencia de los hacendados por el mercado norteamericano por la facilidad hallada para disponer del capital realizado en las transacciones ${ }^{41}$. Eran estímulos suficientes para mantener depósitos en el extranjero; eran otras tantas razones para el trasvase de patrimonios y la paulatina emigración a España, Inglaterra, Francia o Estados Unidos de las antiguas familias, buscando seguridad personal y económica. A causa de la emigración o por fallecimiento, entre 1878 y 1895 desaparece buena parte del grupo social criollo-peninsular tradicional. No solo viajan, sino que desaparecen sus relaciones sociales y parte de la base material insular a la que debían fortuna e influencia. Pero en el exterior se busca también una rentabilidad que el azúcar no estaba en condiciones de proporcionar.

El ministro de Ultramar, José Elduayen, se extrañaba de las protestas procedentes de Cuba sobre los exiguos beneficios obtenidos a la vez que aumentaba la exportación y la importación en la Isla. E indicaba el limitado interés que había despertado en la colonia los títulos de deuda y la emisión de valores del Banco Hispano-Colonial que proporcionaba el $12 \%$ de interés y una participación en el aumento de la recaudación de la renta de adunas, lo que venía a traducirse en un $18 \%$ y un $20 \%$ de rentabilidad. Elduayen erraba al enjuiciar el desinterés cubano por las inversiones industriales y financieras al no tener presente que se producían en la Península o en otros países, y al sobrevalorar los beneficios de la tierra, capaces de enjugar en una zafra las dificultades. Tmpoco tenía presente que un tercio del capital del Banco Hispano Colonial, cinco millones de pesos, había sido suscrito en Cuba en $1876^{42}$.

Sin embargo Elduayen no andaba desencaminado cuando advertía un amplio movimiento de capitales derivado del superavit merp. 45 .

40 "El doble patrón monetario en Cuba", Revista Económica, 90, 13 de julio de 1879,

${ }^{41}$ Miguel BlanCo Herrero, Isla de Cuba. Su situación actual y reformas que reclama, Madrid, Imp. Agustín Jubera, 1876, p. 53.

42 Gaceta de Madrid, 13 de noviembre de 1876. 
cantil: "¿sucede acaso - se interrogaba - que el capital no procura el empleo más beneficioso y más productivo?"43.

El movimiento de capitales hacia otras actividades antecede la crisis azucarera y en la medida en que se orienta a otros destinos en la propia Isla nos indica esa búsqueda alternativa de rentabilidad. La emisión de 1873 de Bonos del Tesoro cubano proporcionaba el 8\% de interés y atrajo capitales de hacendados como Ibáñez Palenciano, Salvador Samá y Francisco Marty, así como de comerciantes como Pérez de la Riva. El incumplimiento de las obligaciones por la Hacienda insular hizo ruinosa su adquisición ${ }^{44}$. Pero en la medida que se dieron garantías, los depósitos fluyeron hacia la adquisición de acciones y títulos. El caso de la deuda española antes citado es revelador: Nicolás Brunet, Ramón Argüelles, Rafael de Toca, Salvador Samá, Francisco Feliciano Ibáñez, Miguel Aldama, Francisco Calderón, José Artocha y Carlos Zaldo, entre otros, habían adquirido títulos españoles cada uno por valor superior a los 200.000 pesos $^{45}$. Como también lo es la relación de mayores suscriptores de acciones del Banco Hispano Colonial: Baró, Zulueta, Moré, Rosell, Calvo, Ibáñez Palenciano...

Los capitales creados en el comercio en parte se destinaron a la adquisición de ingenios y dieron lugar a un nuevo ciclo de sustitución de propietarios, pero en especial se emplearon en el incremento de los intercambios mercantiles con la metrópoli y se orientaron a ramos relacionados con el azúcar pero no con su producción. El caso más importante pudiera ser el de Ramón Argüelles, banquero y comerciante, que asociado a la banca británica Schröder entra en el negocio del ferrocarril reemplazando a la familia Alfonso-Aldama, y en 1889 pasa a presidir el "Banco del Comercio, Ferrocarriles Unidos de La Habana y Almacenes de Regla", acompañado en la secretaría del abogado y hombre de negocios Arturo Amblard ${ }^{46}$. Y en modo alguno puede desdeñarse la inversión en empresas insulares

\footnotetext{
43 José Elduayen, La Hacienda en la Isla de Cuba, Madrid, Impr. Manuel G. Hernández, 1880 , pp. 42-43.

44 Exposición que dirigen a las Cortes los tenedores de bonos del Tesoro de la Isla de Cuba de la emisión de veinte millones de pesos autorizada por el RD de 9 de agosto de 1872, La Habana, Impr. de La Integridad de la Patria, 1879, pp. 25-27.

45 A. BAHAMONDE y G. CAYUEla, [34], p. 153.

46 Oscar ZANETTI y Alejandro GARCíA, Caminos para el azúcar, La Habana, Editorial de Ciencias Sociales, 1987, p. 175.
} 
de bienes de consumo y de servicios, que precisamente en los años 1880 tienen su punto de partida ${ }^{47}$.

Teniendo en cuenta que la maquinaria moderna con la que podía equiparse un central costaba medio millón de pesos ${ }^{48}$, el capital generado por el azúcar que fue transferido al exterior o buscó otros destinos en la Isla hubiera podido financiar con creces la renovación completa de la estructura productiva del azúcar cubano antes de 1890. Pero el hecho fue el inverso: no habiéndose adaptado cuando las condiciones fueron favorables, en medio de la crisis la ausencia de niveles óptimos de rentabilidad y la dificultad de la recuperación ahuyentaron los capitales hacia destinos que proporcionaran mayores beneficios.

This article studies the great hacienda-owners and, in particular, the strategies they applied in order to diversify their income through investment in sugar and other alternative activities, both in and outside Cuba. Investments on these alternative sectors stemmed form return estimations rather than from lack of financial resources.

\footnotetext{
47 María Antonia MARQUÉS DolZ, Empresas y empresarios en las entidades industriales menores de Cuba (1870-1929), Tesis doctoral, Universidad Autónoma de Madrid, 1997, p. 47.

48 Laird W. BERGAD, [10], p. 274.
} 